\title{
ATIVIDADE ANTIOXIDANTE DA POLPA, CASCA E SEMENTES DO NONI (Morinda citrifolia Linn) ${ }^{1}$
}

\author{
ADRIANA BARBOSA COSTA², ADOLFO MARCITO CAMPOS DE OLIVEIRA ${ }^{3}$, \\ ANA MARA DE OLIVEIRA E SILVA ${ }^{4}$, JORGE MANCINI-FILHO ${ }^{5}$, ALESSANDRO DE LIMA $^{6}$
}

RESUMO - Na busca pela identificação de novas fontes de antioxidantes naturais e de esclarecer lacunas acerca das reais propriedades benéficas atribuídas ao Noni (Morinda citrifolia Linn), este trabalho teve como objetivo realizar a caracterização química e avaliar a atividade antioxidante da polpa, casca e sementes do noni. Foram determinadas a composição centesimal (umidade, cinzas, proteínas, carboidratos e lipídios); os compostos bioativos (fenólicos totais, carotenoides totais e vitamina $\mathrm{C}$ ) e a atividade in vitro em extratos aquoso, etanólico e acetônico. Os resultados demonstraram que o Noni possui quantidades significativas de carboidratos $(27,21 \% ; 9,70 \%$ e $8,37 \%)$ e de proteínas $(2,64 \% ; 2,23 \%$; e 2,24\%) nas sementes, casca e polpa, respectivamente. A polpa apresentou maior teor de vitamina $\mathrm{C}(23,1 \mathrm{mg} / 100 \mathrm{~g})$ e de carotenoides totais $(3,90 \mathrm{mg} / 100 \mathrm{~g})$. No extrato acetônico da polpa, foram quantificados $109,81 \mathrm{mg} / 100 \mathrm{~g}$ de fenólicos totais, seguidos pelos extratos acetônicos da casca $(76,01 \mathrm{mg} / 100 \mathrm{~g})$, das sementes $(28,75 \mathrm{mg} / 100 \mathrm{~g})$ e do extrato etanólico da polpa $(20,33 \mathrm{mg} / 100 \mathrm{~g})$. Todos os extratos avaliados apresentaram atividade antioxidante in vitro; os extratos acetônico e etanólico da casca e das sementes do Noni apresentaram maior atividade pelo método $\beta$-caroteno/ ácido linoleico, enquanto o extrato etanólico da polpa teve maior atividade antioxidante pelo ensaio DPPH e ABTS, e o extrato acetônico da polpa, pelo método ABTS. O noni é um fruto com significativo teor de compostos fenólicos totais que apresentam atividade antioxidante in vitro.

Termos para Indexação: fruto, compostos bioativos, antioxidantes.

\section{ANTIOXIDANT ACTIVITY OF THE PULP, SKIN AND SEEDS OF THE NONI (Morinda citrifolia Linn)}

ABSTRACT - In an attempt to identify new sources of natural antioxidants and to clarify gaps in the scientific literature about the real beneficial properties attributed to Noni (Morinda citrifolia Linn), this study aimed to determine the chemical characterization and to evaluate antioxidant activity of the pulp, skin and seeds of Noni. Chemical composition (moisture, ash, protein, carbohydrates and lipids), bioactive compounds (total phenolics, total carotenoids and vitamin C), and the in vitro activity in aqueous, ethanolic and acetone extracts were determined. The results showed that compared to others fruits, the different parts of Noni have significant amounts of carbohydrates $(27.21 \%, 9.70 \%$ and $8.37 \%)$ and protein $(2.64 \%$, $2.23 \%$, and $2.24 \%$ ) in seeds, skin and pulp, respectively. The pulp had a higher content of vitamin C $(23.1 \mathrm{mg} / 100 \mathrm{~g})$ and carotenoids $(3.90 \mathrm{mg} / 100 \mathrm{~g})$. An amount of $109.81 \mathrm{mg} / 100 \mathrm{~g}$ of total phenolics was determined in the acetone extract of the pulp, followed by 76.01 and $28.75 \mathrm{mg} / 100 \mathrm{~g}$ in the acetonic extracts of the skin and seeds, respectively and the ethanolic extract of the pulp with $20.33 \mathrm{mg} / 100 \mathrm{~g}$ ). All extracts showed antioxidant activity in vitro. The acetone and ethanolic extracts of the skin and seeds of Noni showed higher activity by the $\beta$-carotene / linoleic acid method while the ethanolic pulp extract had a higher antioxidant activity by DPPH and ABTS assay and the acetone extract of the pulp by the ABTS method. Data showed that Noni has high content of phenolic compounds with antioxidant capacity in vitro in different parts of the fruit.

Index terms: fruit, bioactive compounds, antioxidant activity.

${ }^{1}$ (Trabalho 192-12). Recebido: 18-06-2013. Aceito para publicação em: 10-05-2013.

${ }^{2}$ Nutricionista. Mestre em Alimentos e Nutrição. Universidade Federal do Piauí - UFPI, Campos Universitário Petrônio Portela, s/n 64049-550 Teresina - Piauí - Brasil -E-mail: dri_bcosta@hotmail.com

${ }^{3}$ Farmacêutico-Bioquímico. Mestre em Alimentos e Nutrição. Universidade Federal do Piauí - UFPI, Campos Universitário Petrônio Portela, s/n 64049-550 Teresina - Piauí - Brasil. E-mail: amcoliveira2@hotmail.com

${ }^{4}$ Doutoranda em Ciência dos Alimentos da Faculdade de Ciências Farmacêuticas - USP. E-mail: anamara@usp.br.

${ }^{5}$ Professor Titular do Departamento de Alimentos e Nutrição Experimental da Faculdade de Ciências Farmacêuticas da Universidade de São Paulo. E-mail: jmancini@usp.br

${ }^{5}$ Professor Adjunto do Instituto Federal de Educação, Ciência e Tecnologia do Piauí - IFPI. Avenida Pedro Freitas, 1020, São Pedro, Teresina, Piauí, CEP: 64001-010. E-mail: alessandro@ifpi.edu.br. 


\section{INTRODUÇÃO}

Os produtos naturais e herbáceos têm sido utilizados durante séculos, por diferentes culturas em todo o mundo, como parte do acervo da medicina tradicional. Dessa forma, o uso de plantas medicinais e seus extratos vêm crescendo na assistência à saúde em função de sua fácil aceitabilidade, disponibilidade e baixo custo (VARANDA, 2006; BALUNAS et al., 2006).

Os compostos bioativos mais comumente encontrados em vegetais, frutas e hortaliças são as substâncias fenólicas, que são formadas no metabolismo secundário dos vegetais, podendo ser encontradas na forma livre ou ligadas a açúcares e proteínas, possuindo várias funções como: crescimento da planta, propriedades sensoriais, processos germinativos da semente, defesa contra pragas e danos oxidativos (LIU, 2007). Já em animais e humanos, os estudos têm apontado que os compostos fenólicos são capazes de bloquear as estruturas radicalares, devendo-se isso à sua estrutura química, formada por, pelo menos, um anel aromático com grupamentos hidroxila (BRAVO, 1998).

$\mathrm{O}$ excesso de radicais livres no organismo leva ao estresse oxidativo (conjunto de condições intra e extracelulares que leva à geração exacerbada de radicais livres, causando desequilíbrio na homeostase). Essa condição tem sido associada como um possível agente causador de uma série de doenças crônicas não transmissíveis, como aterosclerose, infarto do miocárdio, artrite reumatoide, catarata, mal de Parkinson, envelhecimento precoce, câncer, dentre outras. (MANACH E DONOVAN, 2004; KIM et al., 2008).

Estudos em todo o mundo têm caracterizado os vários produtos naturais com o intuito de identificar e quantificar os componentes bioativos destes vegetais a fim de utilizá-los na alimentação da população e, com isso, reduzir o risco de surgimento de doenças ( NEVES, 2012). Nesse contexto, as frutas exóticas, como o Noni (Morinda citrifolia Linn), têm ganhado cada vez mais espaço, tanto pela busca de benefícios que estas possam oferecer, como pela procura por diferentes tipos de fontes alimentares.

O emprego tradicional do Noni, usado há mais de 2.000 anos pelos polinésios, está atribuído aos efeitos relacionados com atividade antibacteriana, antioxidante, antiviral, antifúngica, antitumoral, anti-helmíntica, analgésica, anti-inflamatória, hipotensora e imunoestimulante (WANG et al., 2002).

Esse vegetal tem suas folhas e especialmente seu fruto consumidos sob diferentes formas por diversas comunidades do mundo (CHAN-BLANCO et al., 2006).

Diante da relevância que tem alcançado os estudos sobre as propriedades medicinais da Morinda citrifolia Linn, são de fundamental importância pesquisas que avaliem os reais benefícios que este fruto pode trazer à saúde. Diante do exposto, este trabalho teve como objetivo determinar o valor nutritivo do Noni, bem como avaliar sua atividade antioxidante e antifúngica, nas distintas partes que compõem o fruto (casca, sementes e polpa).

\section{MATERIAL E MÉTODOS}

\section{Material}

As amostras de Noni (Morinda citrifolia Linn.) foram adquiridas no município de Altos, Estado do Piauí - Brasil a $31^{\circ} 12^{\prime \prime} 21^{\prime} \mathrm{O}$ de latitude e a $400 \mathrm{~m}$ de altitude, provenientes de hortas domiciliares, sem uso de adubos no solo e comercializados localmente.Foram coletados 100 frutos maduros (casca amarelo-esbranquiçada e de fácil remoção) e lavados cuidadosamente com água destilada antes da separação das partes. $\mathrm{O}$ fruto foi subdivido em três partes: casca, sementes e polpa. Após a separação das partes, as amostras foram trituradas em moinho analítico (modelo IKA A11 basic), acondicionadas em sacos plásticos envolvidos por papelalumínio e armazenados sob congelamento a $-18^{\circ} \mathrm{C}$, por um período máximo de 30 dias.

\section{MÉTODOS}

Determinação da composição centesimal

A determinação de umidade foi feita pela secagem em estufa a $105^{\circ} \mathrm{C}$ até peso constante. A determinação do resíduo mineral fixo (cinzas) foi realizada pela incineração em mufla a $550^{\circ} \mathrm{C}$. As proteínas foram determinadas pelo método de $\mathrm{Kjel}$ dahl, utilizando o fator de 6,25 para conversão do nitrogênio em proteína. Os lipídeos totais foram obtidos com extração da fração etérea por fluxo intermitente, utilizando éter etílico como solvente sob refluxo, em aparelho de Soxhlet. Os carboidratos foram obtidos por diferença. Todas as análises foram realizadas em triplicata e segundo as normas do Instituto Adolf Lutz (2005).

\section{acetônico \\ Obtenção dos extratos aquoso, alcoólico e \\ Os extratos alcoólicos, acetônicos e aquosos} foram obtidos de forma sequencial, a partir de $20 \mathrm{~g}$ de cada amostra (polpa, sementes e casca do Noni) previamente trituradas, segundo metodologia de Vieira et al. (2011). 
Para a obtenção dos extratos alcoólicos, foram pesados 20 gramas de amostra, na qual foram adicionados $100 \mathrm{~mL}$ de álcool etílico e submetidos à agitação por uma hora, para posterior filtração a vácuo. $\mathrm{O}$ resíduo foi recuperado para a obtenção dos extratos acetônico e aquoso, seguindo o mesmo procedimento utilizado para a obtenção do extrato alcoólico, utilizando-se acetona e água, respectivamente, como diluentes.

\section{Determinação dos fenólicos totais}

A determinação dos fenólicos totais seguiu a metodologia descrita por Swain e Hills (1959). Foi adicionado em um balão volumétrico de $10 \mathrm{~mL}, 0,5$ $\mathrm{mL}$ de amostra, em triplicata, do extrato alcoólico, aquoso e/ou acetônico, $8 \mathrm{~mL}$ de água destilada e 0,5 $\mathrm{mL}$ do reagente de Follin Denis. Em seguida, a solução foi homogeneizada e deixou-se em repouso por $3 \mathrm{~min}$. Decorrido esse tempo, acrescentou-se 1 $\mathrm{mL}$ de solução saturada de carbonato de sódio anidro. A solução ficou em repouso por 1 hora e logo após foram realizadas as leituras de absorbâncias em espectrofotômetro (Coleman 33 D) a $720 \mathrm{~nm}$. A leitura do branco foi realizada contendo os mesmos reagentes, menos a amostra. Utilizou-se como padrão a solução de ácido gálico, em concentrações variando de 0 a $100 \mathrm{mg} / \mathrm{mL}$. O cálculo do teor de fenólicos totais foi expresso em $\mathrm{mg}$ de ácido gálico/g de amostra.

\section{Conteúdo de carotenoides totais}

A determinação dos carotenoides foi realizada segundo AOAC (2000). Os extratos foram preparados a partir de 10 gramas de cada amostra (casca, sementes e polpa) em Erlenmeyer de 250 $\mathrm{mL}$, com adição de $30 \mathrm{~mL}$ de álcool isopropílico e $10 \mathrm{~mL}$ de hexano. A mistura foi homogeneizada durante 1 hora, em frascos Erlenmeyer, usando o agitador magnético e, em seguida, adicionaram-se $85 \mathrm{~mL}$ de água destilada. A solução foi transferida para um funil de separação. Após 30 minutos de repouso, adicionaram-se $10 \mathrm{~mL}$ de água destilada e, em seguida, filtrou-se a mistura. O filtrado foi recolhido em recipiente contendo $5 \mathrm{~mL}$ de acetona, o qual foi completado com hexano até completar $50 \mathrm{~mL}$. Procedeu-se à leitura, em triplicata, destes extratos, em espectrofotometro (Coleman 33 D) a $450 \mathrm{~nm}$. Para o cálculo do teor de carotenoides, foi utilizada a seguinte fórmula:

Carotenoides (mg/100g) $=\frac{\text { Absorbância lida x 100 }}{250 \times \text { L x W }}$
L- caminho ótico;
W- fator de diluição entre a amostra inicial e

o volume final da diluição.

\section{Conteúdo de vitamina $\mathbf{C}$}

Para a determinação do conteúdo em vitamina C (ácido ascórbico), 10 gramas da amostra foram diluídos em $100 \mathrm{~mL}$ de água destilada. Após filtração em papel-fitro, uma alíquota de $10 \mathrm{~mL}$ do filtrado foi transferida para Erlenmeyer de $250 \mathrm{~mL}$, adicionaram-se $10 \mathrm{~mL}$ de ácido oxálico, e a solução foi titulada com 2,6-diclorofenol indofenol como inidicador, sendo o ponto de viragem detectado visualmente com mudança de coloração (BENASSI; ANTUNES,1988).

\section{Atividade antioxidante \\ Método de captura de radicais DPPH (2,2 difenil-1-picril-hidrazil)}

Este método tem por base a redução do radical DPPH', que ao fixar um $\mathrm{H}^{\cdot}$ (removido do antioxidante em estudo), leva a uma diminuição da absorbância. Para a avaliação da atividade antioxidante da polpa, sementes e casca do Noni foram adicionadas a 1,5 mL de solução metanólica de $\mathrm{DPPH} \bullet\left(6 \mathrm{X} 10^{-5} \mathrm{M}\right)$ e uma alíquota de $0,5 \mathrm{~mL}$ das soluções contendo diferentes concentrações de cada extrato. A leitura de absorbância foi realizada em espectrofotômetro (Coleman 33D) a $517 \mathrm{~nm}$, nos tempos de $2 ; 5 ; 10 ; 20$ e 30 minutos após o início da reação. Todas as leituras foram feitas em triplicata e acompanhadas de um controle. A porcentagem de descoloração do radical DPPH foi calculada de acordo com a fórmula:

\section{$\%$ de atividade antioxidante $=\underline{\text { Abs controle }- \text { Abs amostra }} \mathbf{x} 100$ Abs controle}

Para o cálculo dos valores de EC50 (concentração do extrato necessário para reduzir $50 \%$ do radical DPPH) dos distintos extratos, foi calculada a atividade antioxidante em diferentes concentrações, de forma a traçar uma curva entre a capacidade antioxidante do respectivo extrato e sua concentração. Esses dados foram submetidos a uma regressão linear e obtida uma equação da reta para o cálculo do EC50 (BRAND-WYLLIANS et al., 1995).

Método do radical ABTS++ (2,2'azino-
bis-(3-ethylbenzthiazoline-6-sulfonic acid))
Para a determinação da atividade antioxi-
dante pelo método do radical ABTS •+, usou-se a
metodologia descrita por Re et al. (1999). Inicial-
mente, foi formado o radical ABTS $\bullet+$, a partir da
reação de 7 mM de ABTS com $2,45 \mathrm{mM}$ de persul-
fato de potássio, os quais foram incubados à tempe-
ratura ambiente e na ausência de luz, por 16 horas.


Transcorrido esse tempo, a solução foi diluída em etanol até a obtenção de uma solução com absorbância de $0,70( \pm 0,01)$. Para realizar as análises, foram adicionados $40 \mu \mathrm{L}$ da amostra diluída a 1.960 $\mu \mathrm{L}$ da solução contendo o radical e determinou-se a absorbância em espectrofotômetro (Coleman 33 D) a $734 \mathrm{~nm}$, após 20 minutos de reação. Como solução-padrão, usou-se o antioxidante sintético Trolox nas concentrações de 100; 200; 400; 800 e 1.000 $\mu \mathrm{M}$ em etanol. Todas as leituras foram realizadas em triplicata, e os resultados foram expressos em $\mathrm{mM}$ de Trolox por grama de amostra.

\section{do linoleico}

Método de cooxidação do $\beta$-caroteno/áci-

A capacidade antioxidante dos extratos foi avaliada em sistema modelo de cooxidação de substratos: $\beta$-caroteno ácido linoleico, método descrito por Miller (1971). Para o preparo do meio emulsionado, adicionaram-se $20 \mu \mathrm{L}$ de solução de $\beta$-caroteno (Sigma $\left.{ }^{\circledR}\right)$ dissolvido em clorofórmio $(20 \mathrm{mg} / \mathrm{mL}), 40 \mu \mathrm{L}$ de ácido linoleico, $530 \mathrm{mg}$ de emulsificante Tween 40 e $1 \mathrm{~mL}$ de clorofórmio (para completar a emulsificação). A emulsão foi evaporada com nitrogênio gasoso até completa secura. Acrescentaram-se, então, 100 mL de água destilada previamente saturada com oxigênio, por trinta minutos. A solução emulsionada foi diluída até atingir a faixa de densidade ótica, entre $0,6-0,7$ de absorbância em espectrofotômetro a $470 \mathrm{~nm}$.

Em tubos calibrados, foram tomados $5 \mathrm{~mL}$ da solução emulsionada e adicionados a diferentes volumes dos extratos (aquoso, etanólico e acetônico), além do BHT (utilizado como padrão), nas concentrações de 25; 50; 100; 200 e 400 ppm. Todas as determinações foram realizadas em triplicata e acompanhadas de um controle, sem antioxidante.

Imediatamente após a adição da solução emulsionada às substâncias antioxidantes naturais e ao BHT, ou seja, no tempo zero $\left(\mathrm{A}_{0}\right)$, foram realizadas as leituras de cada tubo em espectrofotômetro SPECTRONIC ${ }^{\circledR} 20$ GENESYS TM (ROCHESTER), a $470 \mathrm{~nm}$. A seguir, os tubos foram colocados em banho-maria a $50^{\circ} \mathrm{C}$ e, após um período de duas horas $\left(\mathrm{A}_{f}\right)$, foram realizadas as leituras das absorbâncias.

Os resultados foram expressos em porcentagem de inibição de oxidação, conforme o cálculo expresso na fórmula a seguir:

\section{$\%$ de Oxidação $=\frac{X \text { da Abs. amostra }}{X \text { da }}{ }^{1} \times 100$}

\% de Proteção $=100$ - \% de Oxidação

\section{Análise estatística}

Neste trabalho, os resultados foram expressos como média \pm desvio-padrão. Para a comparação das médias aritméticas, empregaram-se a análise de variância (ANOVA) e o teste de Tukey, usando o software Prisma 4.0 (GraphPad). Adotou-se o nível de significância de $5 \%$ de probabilidade $(\mathrm{p}<0,05)$.

\section{RESULTADOS E DISCUSSÃO}

Os resultados da composição centesimal da polpa, das sementes e da casca do Noni encontram-se dispostos na Tabela 01, na qual se pode observar que a água é componente majoritário no Noni, em todas as partes estudadas. $\mathrm{O}$ valor da umidade no presente estudo foi de $88,36 \% ; 68,65 \%$ e $86,49 \%$ para polpa, semente e casca, respectivamente. Resultados semelhantes, para a polpa do Noni, foram encontrados por Chan-Blanco et al. (2006), que quantificaram $90 \%$ de umidade. O conteúdo de cinzas variou de $0,93 \%$ para a polpa a $1,05 \%$ para a semente.

Os resultados também demonstram que não houve diferenças significativas nos valores de proteínas e lipídeos referentes às três partes do fruto analisadas. $\mathrm{O}$ teor médio de proteína encontrado para a polpa do Noni foi de 2,24\%, valor superior aos encontrados por Shovic e Whistler (2001), e semelhante ao achado por Chunhieng (2003), de 2,5\%. O teor de proteínas das distintas partes do Noni está próximo aos de frutas como tangerina $(2,49 \%)$ e banana $(2,69 \%)$, e superiores aos de abacaxi $(1,45 \%)$ e maracujá $(0,67 \%)$ (GONDIM et al., 2005).

Marques et. al. (2008), estudando a composição centesimal da polpa e da casca da manga, encontraram para tal fruta valores inferiores de proteínas e lipídeos aos encontrados para o Noni, sendo que, para a polpa da manga, os valores de proteínas foram de $0,44 \%$, e para casca, de $1,24 \%$, já o conteúdo de lipídeos para polpa e casca foi de $0,18 \%$ e $0,44 \%$, respectivamente.

Quanto ao teor de proteínas e lipídeos presentes na semente do Noni, os resultados encontrados foram inferiores aos da semente do maracujá, $12,57 \%$ de proteínas e $28,12 \%$ de lipídeos, de acordo com Jorge et al. (2009). Ainda na Tabela 01, observa-se que o valor energético total, equivalente a $100 \mathrm{~g}$ de amostra, para a polpa e a casca, forneceu cerca de 45,77 e 52,40 kcal, respectivamente, valores inferiores aos encontrados para semente $(124,53$ $\mathrm{kcal}$ ), o que permite inferir que a polpa do Noni apresenta baixo valor calórico.

A Tabela 02 apresenta os valores de vitami- 
na $\mathrm{C}$ e de carotenoides totais das partes do Noni. De acordo com essa tabela, os teores de vitamina $\mathrm{C}$ da polpa $(23,1 \mathrm{mg} / 100 \mathrm{~g})$ foram significativamente $(p<0,05)$ maiores que o encontrado para as demais partes do Noni, e a semente apresentou o menor teor de vitamina $\mathrm{C}$, com 1,36 mg/100 g. Esses valores foram inferiores aos encontrados por Barros et al. (2008) e Canuto et al. (2010), que quantificaram na polpa do Noni 105,3 e 51,2 mg/100, respectivamente. Silva e Naves (2001) citam que as discrepâncias nos teores de vitamina $\mathrm{C}$ encontrados nos frutos podem estar relacionadas com o grau de maturação dos frutos analisados, além da metodologia utilizada para quantificação.

$\mathrm{O}$ teor de vitamina $\mathrm{C}$ da polpa e da casca do Noni é superior aos de frutas como: açaí $(10,1$ $\mathrm{mg} / 100 \mathrm{~g})$, bacuri $(0,2 \mathrm{mg} / 100 \mathrm{~g})$, cajá $(0,3 \mathrm{mg} / 100$ $\mathrm{g})$, cupuaçu $(3,3 \mathrm{mg} / 100 \mathrm{~g})$, murici $(0,3 \mathrm{mg} / 100 \mathrm{~g}) \mathrm{e}$ tamarindo $(0,1 \mathrm{mg} / 100 \mathrm{~g})$ (CANUTO et al., 2010).

Quanto ao conteúdo de carotenoides (Tabela 2), não houve diferença estatística entre os valores obtidos para a polpa $(3,90 \mathrm{mg} / 100 \mathrm{~g})$ e para a casca (3,60 mg/100 g) do Noni, porém ambos foram superiores ao teor de carotenoides obtidos na semente, que foi de $1,06 \mathrm{mg} / 100 \mathrm{~g}$, valor este superior ao obtido por Lima et al. (2007) para a amêndoa do pequi (Caryocar brasiliense, Camb.), de 0,295 mg/100 g. Melo e Andrade (2010), avaliando os carotenoides totais do umbu maduro e semimaduro, encontraram, para a polpa, valores inferiores ao do Noni, de 3,02 e $1,70 \mathrm{mg} / 100 \mathrm{~g}$ respectivamente, enquanto Lima et al. (2007) encontraram para a polpa do pequi um teor de carotenoides de $7,25 \mathrm{mg} / 100 \mathrm{~g}$.

$\mathrm{O}$ extrato acetônico foi mais eficiente na extração de fenólicos (Tabela 3). Dentre os resultados obtidos, o extrato acetônico da polpa foi o que apresentou maior teor de compostos fenólicos, $109,8 \mathrm{mg} / 100 \mathrm{~g}$, diferente estatisticamente $(\mathrm{p}<0,05)$ dos demais extratos. Chan-Blanco et al.(2006) encontraram no extrato aquoso da polpa do Noni 51,1 $\mathrm{mg} / 100 \mathrm{~g}$. Roesler et al. (2007), analisando frutos do cerrado quanto ao teor de fenólicos a partir do extrato etanólico e aquoso de cada fruta, obtiveram para os extratos aquosos da polpa da banha de galinha (Swartizia Langs-dorffi) $(1,59 \mathrm{mg} / 100 \mathrm{~g})$, valor inferior ao extrato aquoso do Noni $(12,75 \mathrm{mg} /$ $100 \mathrm{~g}$ ) e para o araticum (Annona crassiflora Mart), $16,91 \mathrm{mg} / 100 \mathrm{~g}$. Para o extrato aquoso da semente da banha de galinha, o teor de fenólicos foi um pouco superior ao do extrato aquoso da semente do Noni $(2,91 \mathrm{mg} / 100 \mathrm{~g})$.

Ainda de acordo com Roesler et al. (2007), para o extrato etanólico da banha de galinha, foram encontrados para a polpa $(4,68 \mathrm{mg} / 100 \mathrm{~g})$, araticum
$(20,31 \mathrm{mg} / 100 \mathrm{~g})$ e para cagaita (Eugenia dysenterica), valor de $18,31 \mathrm{mg} / 100 \mathrm{~g}$, tanto para o extrato etanólico da polpa como da casca. Pode-se inferir, de acordo com esses resultados, que o extrato etanólico do Noni possui teor considerável de fenólicos totais quando comparado a outros frutos.

Atualmente, não existe um método oficial para a determinação da atividade antioxidante em alimentos de origem vegetal e seus subprodutos, tendo em vista os vários mecanismos antioxidantes que podem ocorrer, bem como a diversidade de compostos bioativos. A literatura descreve vários métodos antioxidantes, cada um com um princípio distinto que utilizam radicais livres e/ ou padrões diversos. Dessa forma, os estudos que visam a avaliar propriedades antioxidantes de extratos vegetais utilizam mais de uma metodologia para inferir, com maior segurança, se os extratos analisados poderão apresentar, também, alguma atividade em combater os radicais livres formados no interior do organismo humano (SOUSA et al., 2011).

Entre as metodologias que têm sido utilizadas, destacam-se as que utilizam os radicais DPPH e ABTS+, além do método de cooxidação do $\beta$-caroteno ácido linoleico, pela facilidade de execução e pela boa correlação com as demais metodologias antioxidantes. Neste contexto, Vedana et al. (2008) encontraram uma correlação positiva para a atividade antioxidante de extratos aquosos e hidroalcoólicos de uvas, da cultivar Isabel, quando avaliados pelos métodos do DPPH e ABTS+. Entretanto, essa regra não é geral para todos os antioxidantes, pois Villaño et al. (2006) constataram que os ácidos fenólicos siríngico, vanílico e p-cumárico, e a procianidina $\mathrm{B} 3$ não reagem com o radical ABTS+; entretanto, apresentam elevada atividade antioxidante pelo método DPPH.

Não existe sistema de extração com solventes que seja satisfatório para o isolamento de todos ou de classe específica de antioxidantes naturais, devido a diversos fatores. A natureza química desses compostos nos alimentos varia do simples ao altamente polarizado, a grande variedade de compostos bioativos nos vegetais (como os ácidos fenólicos, antocianinas e taninos) e diferentes quantidades presentes, além da possibilidade de interação dos compostos antioxidantes com carboidratos, proteínas e outros componentes dos alimentos (SHAHIDI; NACZK, 1995; SOUSA et al., 2011). Portanto, neste estudo, foram utilizados os solventes mais citados na literatura como mais eficientes na extração de compostos com atividade antioxidante.

A capacidade em sequestrar os radicais DPPH foi avaliada utilizando concentrações dis- 
tintas para cada extrato, variando de acordo com a resposta antioxidante de cada um. Uma curva linear foi obtida entre a concentração do antioxidante e o sequestro do radical, calculando-se, a partir disso, o $\mathrm{EC}_{50}$ de cada extrato. Conforme disposto na Tabela 04 , todos os extratos apresentaram atividade em sequestrar o radical DPPH, e o extrato etanólico da polpa de noni foi o que apresentou melhor atividade antioxidante $\left(\mathrm{EC}_{50}=40,98 \mu \mathrm{g} / \mathrm{mL}\right)$, seguido pelo extrato etanólico da casca $\left(\mathrm{EC}_{50}=103,2 \mu \mathrm{g} /\right.$ $\mathrm{mL})$, acetônico da casca $\left(\mathrm{EC}_{50}=105,79 \mu \mathrm{g} / \mathrm{mL}\right)$ e acetônico da semente $\left(\mathrm{EC}_{50}=108,19 \mu \mathrm{g} / \mathrm{mL}\right)$. Os extratos aquosos da polpa e da semente apresentaram atividade antioxidante apenas em elevadas concentrações $(600-1.400 \mu \mathrm{g} / \mathrm{mL})$, com os maiores resultados para o $\mathrm{EC}_{50}$, que foi de $1.401 \mu \mathrm{g} / \mathrm{mL} \mathrm{e}$ $739,67 \mu \mathrm{g} / \mathrm{mL}$, respectivamente, o que provavelmente ocorreu pelo seu baixo teor em fenólicos totais (Tabela 3).

Lima (2008), avaliando a capacidade antioxidante do extrato etanólico da polpa do pequi, pelo método DPPH, encontrou valor de $\mathrm{EC}_{50}(820,37 \mu \mathrm{g} /$ $\mathrm{mL}$ ) inferior ao encontrado neste estudo, Roesler et al. (2007), avaliando a capacidade antioxidante de frutas do cerrado brasileiro, encontraram valores de $\mathrm{EC}_{50}$, para os extratos aquosos e etanólicos da polpa, respectivamente, de $879,93 \mu \mathrm{g} / \mathrm{mL}$ e $387,47 \mu \mathrm{g} /$ $\mathrm{mL}$ para cagaita, $1.321,93 \mu \mathrm{g} / \mathrm{mL}$ e $148,82 \mu \mathrm{g} / \mathrm{mL}$ para o araticum e $1.328,98 \mu \mathrm{g} / \mathrm{mL}$ e $182,16 \mu \mathrm{g} / \mathrm{mL}$ para a lobeira. Jorge et al. (2009), analisando o extrato etanólico da semente do maracujá, obtiveram $\mathrm{EC}_{50}$ de $113,41 \mu \mathrm{g} / \mathrm{mL}$.

Para a avaliação da atividade antioxidante dos extratos da polpa, sementes e casca do Noni pelo método $\beta$-caroteno/ ácido linoleico, foram utilizados cinco tipos de concentrações diferentes (25; 50; 100; 200 e 400 ppm), de tal forma que a reação dos antioxidantes das amostras e do BHT (padrão) reagissem com o sistema emulsionado com consequente queda na densidade óptica após 120 minutos. A capacidade antioxidante dos extratos aquosos, etanólicos e acetônicos estão demonstrados na Tabela 05. Pode-se inferir que os três extratos, principalmente nas concentrações de 100; 200 e 400 ppm, apresentaram boa atividade em combater os peróxidos formados, comparados com o padrão BHT. Pode-se constatar que, relacionando as partes (polpa, sementes e casca) do Noni, com seus respectivos percentuais de proteção, a menor atividade foi conferida pela polpa, sendo as sementes e a casca as partes que apresentaram melhores percentuais de proteção da oxidação.

Lima (2008), avaliando a capacidade de proteção da polpa do pequi, encontrou para o ex- trato alcoólico, na concentração de 200 ppm, 18,3\% $\pm 0,10$ de proteção, valor este semelhante ao encontrado para o extrato alcoólico da polpa do Noni $(17,74 \% \pm 0,55)$.

Jardini e Mancini Filho (2007), avaliando a atividade antioxidante em diferentes extratos da polpa e sementes da romã, pelo teste de cooxidação com $\beta$-caroteno/ ácido linoleico, encontraram para extrato alcoólico da semente, na concentração de 200 ppm, proteção de $35,41 \% \pm 6,53$, valor próximo ao encontrado para o Noni, de $35,96 \% \pm 1,03$ para o mesmo extrato (Tabela 05). Pelo mesmo método, Giada e Mancini-Filho (2006) observaram que, na concentração de 200 ppm, os extratos aquoso e alcoólico da semente de girassol apresentaram uma proteção de 35,1 e 4,2\%, respectivamente, após duas horas de ensaio.

A porcentagem de proteção conferida pelos extratos de Noni foram menores que o padrão BHT $(\mathrm{p}<0,05)$, porém, em concentrações maiores (400 ppm), os extratos etanólicos e acetônicos da casca e da semente superaram valores de proteção acima de 50\% (Tabela 05), o que pode sugerir que esses extratos possuem boa atividade em inibir a oxidação em concentrações acima de 400 ppm.

$\mathrm{Na}$ Tabela 06, são expressos os valores TEAC (capacidade antioxidante total do composto equivalente ao Trolox), dos extratos de Noni. O extrato acetônico da polpa apresentou maior atividade antioxidante $(p<0,05)$ em todos os tempos, com TEAC variando de $1,33 \mathrm{mM} / \mathrm{g} \pm 0,03$ no tempo de 2 minutos a $1,67 \mathrm{mM} / \mathrm{g} \pm 0,03$ no tempo de 60 minutos. Os valores de TEAC encontrados neste estudo, entretanto, foram inferiores aos detectados por Jáurequi et al. (2007), que quantificaram um TEAC de $3,48 \mathrm{mM} / \mathrm{g}$ de amostra.

Os extratos alcoólicos da polpa (TEAC $=$ $1,17 \mathrm{mM} / \mathrm{g} \pm 0,00)$ e da casca (TEAC $=1,09 \mathrm{mM} / \mathrm{g}$ $\pm 0,01$ ), no tempo de 30 minutos (Tabela 6) apresentaram boa atividade antioxidante. Valores próximos aos de frutos como pequi (TEAC $=0,95 \mathrm{mM} /$ $\mathrm{g} \pm 0,14)$ (LIMA, 2008) e superiores aos de frutos como bacuri (TEAC $=0,6 \mathrm{mM} / \mathrm{g} \pm 0,30$ ) e cupuaçu (TEAC $=0,6 \mathrm{mM} / \mathrm{g} \pm 0,20)$, de acordo com Canuto et al.(2010). Já Villaño et al. (2006) encontraram valores de TEAC de $1,98 \mathrm{mM} / \mathrm{g}$ para o ácido gálico; $1,01 \mathrm{mM} / \mathrm{g}$ para o ácido cafeico; $0,99 \mathrm{mM} / \mathrm{g}$ para a epicatequina; e $1,83 \mathrm{mM} / \mathrm{g}$ para a procianidina $\mathrm{B}_{2}, \mathrm{o}$ que demonstra que os extratos alcoólicos da polpa e da casca apresentam atividade antioxidante comparável a padrões de ácidos fenólicos puros.

Os extratos aquosos da casca, da polpa e das sementes apresentaram os menores valores de TEAC e inferiores $(p<0,05)$ em relação aos extratos 
alcoólicos e acetônicos. Provavelmente, os compostos antioxidantes presentes nesses extratos possuem baixa reatividade com o radical ABTS. Por isso a importância da realização da atividade antioxidante de matrizes alimentares por distintas metodologias.
Villaño et al. (2006) descrevem que mesmo padrões de ácidos fenólicos puros, como os ácidos siríngico, vanílico, p-cumárico e a procianidina B3 não possuem atividade antioxidante com o radical ABTS.

TABELA 1- Composição centesimal da polpa, da semente e da casca do Noni (Morinda citrifolia Linn.).

\begin{tabular}{cccc}
\hline Constituintes & Polpa (\%) & Semente (\%) & Casca (\%) \\
\hline Umidade & $88,36 \pm 0,22 \mathrm{a}$ & $68,65 \pm 1,03 \mathrm{c}$ & $86,49 \pm 0,36 \mathrm{~b}$ \\
Cinzas & $0,93 \pm 0,03 \mathrm{~b}$ & $0,93 \pm 0,26 \mathrm{~b}$ & $1,05 \pm 0,13 \mathrm{a}$ \\
Proteína & $2,24 \pm 0,04 \mathrm{a}$ & $2,64 \pm 0,03 \mathrm{a}$ & $2,23 \pm 0,40 \mathrm{a}$ \\
Lipídeos & $0,37 \pm 0,01 \mathrm{a}$ & $0,57 \pm 0,01 \mathrm{a}$ & $0,52 \pm 0,07 \mathrm{a}$ \\
Carboidratos & $8,37 \pm 0,43 \mathrm{c}$ & $27,21 \pm 0,82 \mathrm{a}$ & $9,70 \pm 0,55 \mathrm{~b}$ \\
VET & 45,77 & 124,53 & 52,40 \\
\hline
\end{tabular}

Valores expressos em média \pm desvio-padrão, $\mathrm{n}=3$

a,b,c Médias seguidas da mesma letra nas linhas não diferem estatisticamente entre si, pelo teste de Tukey, a nivel de 5\% de probabilidade.

VET:Valor energético total

TABELA 2 - Teor de vitamina C e de carotenoides da polpa, de casca e da semente do Noni (Morinda citrifolia Linn.) em mg/ $100 \mathrm{~g}$ de amostra.

\begin{tabular}{cccc}
\hline Constituintes & Polpa & Casca & Semente \\
\hline Vitamina C & $23,10 \pm 0,1 \mathrm{a}$ & $10,55 \pm 0,34 \mathrm{~b}$ & $1,36 \pm 0,14 \mathrm{c}$ \\
Carotenoides & $3,90 \pm 0,05 \mathrm{a}$ & $3,60 \pm 0,10 \mathrm{~b}$ & $1,06 \pm 0,10 \mathrm{c}$
\end{tabular}

Valores expressos em média \pm desvio-padrão, $n=3$

a,b,c Médias seguidas da mesma letra nas linhas não diferem estatisticamente entre si, pelo teste de Tukey, ao nivel de 5\% de probabilidade.

TABELA 3 - Teores de fenólicos totais (expresso em equivalente de ácido gálico) presente no extrato aquoso, etanólico e acetônico da polpa, da casca e da semente do Noni (Morinda citrifolia Linn.)

\begin{tabular}{cccc}
\hline Extratos & \multicolumn{3}{c}{$\begin{array}{c}* \text { Teores de fenólicos totais } \\
(\mathbf{m g} / \mathbf{1 0 0} \text { g de amostra) }\end{array}$} \\
\hline & polpa & casca & semente \\
\hline Aquoso & $12,75 \pm 0,26 \mathrm{c}$ & $8,23 \pm 0,13 \mathrm{c}$ & $2,91 \pm 0,47 \mathrm{c}$ \\
Etanólico & $20,33 \pm 1,37 \mathrm{~b}$ & $18,82 \pm 1,26 \mathrm{~b}$ & $11,22 \pm 1,63 \mathrm{~b}$ \\
Acetônico & $109,81 \pm 2,02 \mathrm{a}$ & $76,01 \pm 6,36 \mathrm{a}$ & $28,75 \pm 1,07 \mathrm{a}$ \\
\hline
\end{tabular}

* valores correspondem à média \pm desvio-padrão, $\mathrm{n}=3$

a,b,c Médias seguidas da mesma letra nas colunas não diferem estatisticamente entre si, pelo teste de Tukey, ao nivel de 5\% de probabilidade.

TABELA 4 - Capacidade antioxidante, expressa em $\mathrm{EC}_{50}(\mu \mathrm{g} / \mathrm{mL})$ dos extratos da polpa, da semente e da casca do Noni (Morinda citrifolia Linn) utilizando o radical livre DPPH.

\begin{tabular}{cccc}
\hline Extratos & \multicolumn{3}{c}{$\mathbf{E C}_{\mathbf{5 0}} \mathbf{e m} \boldsymbol{\mu g} / \mathbf{m L}$} \\
\hline Polpa & Semente & Casca \\
\hline Equoso & $1.401,00 \mathrm{c}$ & $739,67 \mathrm{c}$ & $598,90 \mathrm{c}$ \\
Acetônólico & $40,98 \mathrm{a}$ & $498,77 \mathrm{~b}$ & $103,02 \mathrm{a}$ \\
& $507,50 \mathrm{~b}$ & $108,19 \mathrm{a}$ & $105,79 \mathrm{~b}$
\end{tabular}

a,b,c Médias seguidas da mesma letra nas colunas não diferem estatisticamente entre si, pelo teste de Tukey, ao nivel de 5\% de probabilidade. 
TABELA 5- Atividade antioxidante dos extratos aquoso, etanólico e acetônico da polpa, da casca e da semente de Noni (Morinda citrifolia Linn.), pelo método $\beta$-caroteno/ ácido linoleico.

\begin{tabular}{lcccccc}
\hline Extratos & \multicolumn{6}{c}{ \% inibição da oxidação Concentração (ppm) } \\
\hline \multirow{2}{*}{ Aquoso } & Polpa & $5,45 \pm 0,98 \mathrm{aB}$ & $6,13 \pm 0,99 \mathrm{aC}$ & $6,65 \pm 1,62 \mathrm{aB}$ & $6,70 \pm 1,19 \mathrm{bB}$ & $7,16 \pm 0,40 \mathrm{bB}$ \\
& Casca & $8,71 \pm 0,30 \mathrm{aB}$ & $11,23 \pm 1,10 \mathrm{aB}$ & $13,36 \pm 1,39 \mathrm{aA}$ & $17,56 \pm 17,56 \mathrm{bA}$ & $17,80 \pm 0,68 \mathrm{bA}$ \\
& Semente & $15,10 \pm 0,71 \mathrm{aA}$ & $29,46 \pm 0,39 \mathrm{aA}$ & $30,52 \pm 0,69 \mathrm{aA}$ & $30,48 \pm 1,28 \mathrm{bA}$ & $32,19 \pm 1,38 \mathrm{bA}$ \\
\multirow{2}{*}{ Etanólico } & Polpa & $3,37 \pm 1,32 \mathrm{aB}$ & $4,04 \pm 1,32 \mathrm{bC}$ & $6,59 \pm 1,21 \mathrm{abB}$ & $17,74 \pm 0,55 \mathrm{aB}$ & $31,69 \pm 1,08 \mathrm{aB}$ \\
& Casca & $5,94 \pm 1,10 \mathrm{aB}$ & $8,27 \pm 0,81 \mathrm{bB}$ & $19,63 \pm 0,70 \mathrm{abA}$ & $31,57 \pm 1,15 \mathrm{aA}$ & $54,36 \pm 1,24 \mathrm{aA}$ \\
& Semente & $12,17 \pm 1,72 \mathrm{aA}$ & $16,58 \pm 1,22 \mathrm{bA}$ & $23,17 \pm 1,96 \mathrm{abA}$ & $35,96 \pm 1,03 \mathrm{aA}$ & $54,59 \pm 0,54 \mathrm{aA}$ \\
\multirow{2}{*}{ Acetônico } & Polpa & $1,46 \pm 0,29 \mathrm{bB}$ & $2,03 \pm 0,55 \mathrm{bC}$ & $4,05 \pm 0,77 \mathrm{bB}$ & $13,12 \pm 1,14 \mathrm{aB}$ & $26,17 \pm 1,53 \mathrm{aB}$ \\
& Casca & $3,16 \pm 0,33 \mathrm{bB}$ & $7,75 \pm 0,79 \mathrm{bB}$ & $16,59 \pm 0,91 \mathrm{bA}$ & $35,51 \pm 1,05 \mathrm{aA}$ & $58,36 \pm 0,69 \mathrm{aA}$ \\
& Semente & $5,35 \pm 1,51 \mathrm{bA}$ & $8,38 \pm 0,78 \mathrm{bA}$ & $10,88 \pm 1,45 \mathrm{bA}$ & $28,07 \pm 1,45 \mathrm{aA}$ & $50,00 \pm 1,85 \mathrm{aA}$ \\
& & $43,13 \mathrm{c}$ & $60,51 \mathrm{c}$ & $75,53 \mathrm{c}$ & $81,86 \mathrm{c}$ & $87,56 \mathrm{c}$ \\
\hline
\end{tabular}

a,b,A,B,C Médias seguidas de mesma letra, nas colunas, não apresentam diferença estatística entre si, pelo teste de Tukey, a 5\%de probabilidade; letras minúsculas, entre extratos; letras maiúsculas, entre partes.

BHT: Butil Hidroxi Tolueno

TABELA 6- Capacidade Antioxidante Total (TEAC) dos extratos aquoso, alcoólico e acetônico da polpa, da casca e da semente do Noni (Morinda citrifolia Linn) pelo método ABTS $^{++}$expressos em $\mathrm{mM}$ de trolox/g de amostra fresca.

\begin{tabular}{cccccccc}
\hline \multirow{2}{*}{ Extratos } & & \multicolumn{7}{c}{ Valor de TEAC } \\
& & $\mathbf{2}$ & $\mathbf{5}$ & $\mathbf{1 0}$ & $\mathbf{1 5}$ & $\mathbf{2 0}$ & $\mathbf{3 0}$ \\
\hline Alcoólico & Polpa & $1,02 \pm 0,04 \mathrm{~b}$ & $1,07 \pm 0,04 \mathrm{~b}$ & $1,12 \pm 0,04 \mathrm{~b}$ & $1,13 \pm 0,57 \mathrm{~b}$ & $1,15 \pm 0,57 \mathrm{~b}$ & $1,17 \pm 0,00 \mathrm{~b}$ \\
& Semente & $0,42 \pm 0,03 \mathrm{de}$ & $0,46 \pm 0,06 \mathrm{c}$ & $0,52 \pm 0,04 \mathrm{e}$ & $0,55 \pm 0,05 \mathrm{e}$ & $0,57 \pm 0,04 \mathrm{e}$ & $0,60 \pm 0,05 \mathrm{e}$ \\
& Casca & $0,93 \pm 0,03 \mathrm{c}$ & $0,96 \pm 0,04 \mathrm{~b}$ & $1,00 \pm 0,04 \mathrm{c}$ & $1,03 \pm 0,02 \mathrm{c}$ & $1,05 \pm 0,02 \mathrm{c}$ & $1,09 \pm 0,01 \mathrm{c}$ \\
Aquoso & Polpa & $0,10 \pm 0,20 \mathrm{~g}$ & $0,17 \pm 0,01 \mathrm{~d}$ & $0,22 \pm 0,00 \mathrm{~g}$ & $0,25 \pm 0,01 \mathrm{f}$ & $0,27 \pm 0,01 \mathrm{fg}$ & $0,29 \pm 0,01 \mathrm{fg}$ \\
& Semente & $0,17 \pm 0,00 \mathrm{f}$ & $0,23 \pm 0,01 \mathrm{~d}$ & $0,28 \pm 0,01 \mathrm{f}$ & $0,31 \pm 0,01 \mathrm{f}$ & $0,34 \pm 0,01 \mathrm{f}$ & $0,37 \pm 0,01 \mathrm{f}$ \\
& Casca & $0,13 \pm 0,02 \mathrm{fg}$ & $0,18 \pm 0,02 \mathrm{~d}$ & $0,23 \pm 0,03 \mathrm{fg}$ & $0,25 \pm 0,02 \mathrm{f}$ & $0,24 \pm 0,01 \mathrm{~g}$ & $0,27 \pm 0,01 \mathrm{~g}$ \\
Acetônico & Polpa & $1,33 \pm 0,03 \mathrm{a}$ & $1,44 \pm 0,03 \mathrm{a}$ & $1,51 \pm 0,02 \mathrm{a}$ & $1,55 \pm 0,03 \mathrm{a}$ & $1,60 \pm 0,02 \mathrm{a}$ & $1,67 \pm 0,02 \mathrm{a}$ \\
& Semente & $0,47 \pm 0,03 \mathrm{~d}$ & $0,54 \pm 0,06 \mathrm{c}$ & $0,62 \pm 0,05 \mathrm{~d}$ & $0,70 \pm 0,02 \mathrm{~d}$ & $0,74 \pm 0,02 \mathrm{~d}$ & $0,79 \pm 0,02 \mathrm{~d}$ \\
& Casca & $0,51 \pm 0,04 \mathrm{~d}$ & $0,57 \pm 0,05 \mathrm{c}$ & $0,63 \pm 0,04 \mathrm{~d}$ & $0,67 \pm 0,06 \mathrm{~d}$ & $0,70 \pm 0,05 \mathrm{~d}$ & $0,74 \pm 0,05 \mathrm{~d}$ \\
\hline
\end{tabular}

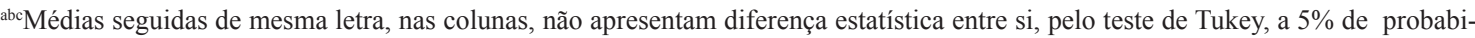
lidade.

\section{CONCLUSÃO}

1-A polpa, a casca e as sementes do Noni possuem alto teor de umidade, quantidades significativas de carboidratos e proteínas, e apenas traços de lipídeos.
2-As distintas partes do Noni apresentam teores variáveis dos compostos bioativos (vitamina $\mathrm{C}$ e carotenoides totais), com destaque para a polpa como maior fonte de vitamina C. Já com relação ao teor de carotenoides totais, tanto a polpa quanto a casca constituem boas fontes desse nutriente.Os teores de fenólicos totais extraídos em meio acetônico são superiores aos encontrados nos extratos aquoso e etanólico, e superiores aos encontrados 
para muitas frutas típicas do cerrado brasileiro nos diferentes meios extratores.

3-Na avaliação da atividade antioxidante in vitro, todos os extratos apresentam expressiva atividade antioxidante, variando em função da porção do fruto e/ou do extrato testado. No método do $\beta$-caroteno/ ácido linoleico a melhor atividade antioxidante é obtida pelos extratos etanólicos e acetônicos da casca e das sementes do Noni, enquanto o extrato alcoólico da polpa maior atividade antioxidante pelos ensaios DPPH e ABTS. O extrato acetônico da polpa também apresenta elevada atividade antioxidante no método ABTS, demonstrando que a polpa do Noni possui elevada capacidade em combater os radicais livres de DPPH e ABTS.

\section{REFERENCIAS}

AOAC - Association of Official Analytical Chemists. Official methods of analysis of AOAC International. $17^{\text {th }}$ ed. Arlington, 2000. v.2.

BALUNAS, M. J.; JONES, W. P.; CHIN, Y.; MI, Q.; FARNSWORTH, N. R.; SOEJARTO, D. D.; CORDELL, G. A.; SWANSON, S. M.;PEZZUTO, J. M.; CHAI, H.; KINGHORN, A. D. Relationships between inhibitory activity against a cancer cell line panel, profiles of plants collected, and compound classes isolated in an anticancer drug discovery project. Chemistry \& Biodiversity, Malden, v.3, p.897-915, 2006.

BENASSI, M.T.; ANTUNES, A.J.A. Comparison of meta-phosphoric and oxalic acids as extractant solutions for the determination of vitamin $\mathrm{C}$ in selected vegetables. Arquivos de Biologia e Tecnologia, Curitiba, v.31, n.4, p.507-513, 1988.

BRAND-WILLIAMS, W.; CUVELIER, M.E.; BERSET, C. Use of a free radical method to evaluate antioxidant activity. Lebensmittel-Wissenschaft und-Technologie, London, v.28, n.1, p.25-30, 1995.

BRAVO, L. Polyphenols: Chemistry, dietary sources, metabolism and nutritional significance. Nutrition Reviews, Lawrence, v.56, n.11, p.317333, 1998.

CANUTO, G. A. B; XAVIER, A. A. O; NEVES, L. C; BENASSI, M. T; Caracterização físico-química de polpas de frutos da Amazônia e sua correlação com a atividade anti-radical livre. Revista Brasileira de Fruticultura, Jaboticabal,v.32, n.4, dez. 2010.
CHAN-BLANCO, Y.; VAILLAN, F.; PEREZ, A. M.; REYNES, M.; BRILLOUET, J.; BRAT, P. The noni fruit (Morinda citrifolia L.): A review of agricultural research, nutritional and therapeutic properties. Journal of Food Composition and Analysis, London, v.19, n.6-7, p.645-654, 2006.

CHUNHIENG, T. Developpement de nouveaux neutraceutiques a partir de graines et fruits d'origine tropicale: application a la noix du Bresil Bertholettia excelsa et au fruit de Cambodge Morinda citrifolia. 2003. $181 \mathrm{f}$. These (Docteur es Procedes biotechnologiques et alimentaires) - Centro de Sciences, Universite de Nancy, Lorraine, 2003.

GIADA, M. D. L. R.; MANCINI FILHO, J. Antioxidant capacity of the striped sunflower (Helianthus annuus L.) seed extracts evaluated by three in vitro methods. International Journal of Food Sciences and Nutrition, Parma, v. 60, p. 395401, 2009.

GONDIM, J. A. M; MOURA; M. F. V; DANTAS, A. S; MEDEIROS, R. L. S; SANTOS, K. M. Composição centesimal e de minerais em casca de frutas. Ciência e Tecnologia de Alimentos, Campinas, v.25, p.825-827, 2005.

INSTITUTO ADOLF LUTZ. Métodos físicoquímicos para análise de alimentos. 4.ed. São Paulo, 2005.

JARDINI, F. A.; MANCINI FILHO, J. Avaliação da atividade antioxidante em diferentes extratos da polpa e sementes da romã (Punica granatumL.). Revista Brasileira de Ciências Farmacêuticas, São Paulo, v. 43, n. 1, p. 137-147, 2007.

JÁUREGUI, A. M. M; RAMOS-ESCUDEIRO, D. F; URETA, C. A. D; CASTAÑEDA, B. C; Evaluación de la capacidade antioxidante $\mathrm{y}$ contenido de compuestos fenólicos em recursos vegetables promisorios. Revista de La sociedad Química Del Peru, Lima, v. 23, n.3, p.142-149, 2007.

JORGE, N; MALACRIDA, C. R; ANGELO, P. M; ANDREO, D. Composição centesimal e atividade antioxidante do extrato de sementes de maracujá (Passiflora edulis) em óleo de soja. Pesquisa Agropecuária Tropical, Goiânia, v.39, n.4, p.380385, 2009. 
KIM, Y; GIRAUD, D. W.; DRISKELL, J. A. Tocopherol and carotenoid contents of selected Korean fruits and vegetables. Journal of Food Composition and Analysis, Netherlands, v. 20, n. 6, p. 458-465, 2008.

LIMA, A. Caracterização química, avaliação da atividade antioxidante in vitro $e$ in vivo $e$ identificação dos compostos fenólicos presentes no pequi (Caryocar brasiliense Camb.). 2008. 186 f. Tese (Doutorado em Ciência dos Alimentos) Faculdade de Ciências Farmacêuticas, Universidade de São Paulo, São Paulo, 2008.

LIMA, A.; SILVA, A.M.O; TRINDADE, R.A.; TORRES, R.P.; MANCINI-FILHO, J. Composição química e compostos bioativos presentes na polpa e na amêndoa do pequi (Caryocar brasiliense, Camb.). Revista Brasileira de Fruticultura, Jaboticabal, v. 29, n. 3, p. 695-698, 2007.

LIU, R.H. Whole grain phytochemicals and health. Journal of Cereal Science, Manhattan, v.46, p.207-219, 2007

MANACH, C.; DONOVAN, J. Pharmacokinetics and metabolism of dietary flavonoids in humans. Free Radical Research, Sidney, v.38, n.8, p.771785, 2004.

MARQUES, A. P. S.; CHICAYBAM, G.; TARANTO, M.; MANHÃES, L. R. T. Comparação da composição centesimal da casca de manga Tommy (Mangifera indica L) e da casca de melancia (Citrullus lanatus) com suas respectivas polpas. Revista da Associação Brasileira de Nutrição, Rio de Janeiro, v.1, n.1, p. 100-100, 2008.

MELO, E. A; ANDRADE, R. A. M. S; Compostos bioativos e potencial antioxidante de frutos do umbuzeiro. Alimentos e Nutrição, São Paulo, v.21, n.3, p. 453-457, 2010.

MILLER, H. E. Simplified method for evaluation of antioxidants. Journal of the American Oil Chemistis Society, Chicago, v.48, n.2, p.91, 1971.

NEVES, L. C. Frutos - O remédio do futuro. Revista Brasileira de Fruticultura, Jaboticabal, v. 34, n.4. p. i, 2012.

RE, R; PELEGRINI, N.; PROTEGGENTE, A.; PANNALA, A.; YANG, M.; RICEEVANS, C. Antioxidant activity applying an improved ABTS radical cation decolorization assay. Free Radical Biology \& Medicine, New York, v.26, n.9-10, p.1231-1237, 1999.
ROESLER, R; MALTA, L. G; CARRASCO, L. C; HOLANDA, R. B; SOUSA, C. A. S; PASTORE, G.M. Atividade antioxidante de frutas do serrado. Ciência e Tecnologia dos Alimentos, Campinas, v. 27, n.1, p.53-60, 2007.

SAHIDI, F; NAAZK, M. Food fenolics: sources, chemistry, effects and applications. Lancaster: Technomic Publishing, 1995. p. 281-319.

SHOVIC A.C; WHISTLER, W.A. Food sources of provitamin $\mathrm{A}$ and vitamin $\mathrm{C}$ in the American Pacific. Tropical Science, London, v.41, n.4, p.199202, 2001.

SILVA, C.R.M, NAVES, M.M.V. Suplementação de vitaminas na prevenção de câncer. Nutrire, São Paulo, v.14, n.2, p.135-43, 2001.

SOUSA, M. S. B.; Vieira, L, M; SILVA, A. O; MANCINI-FILHO, J; LIMA, A. Caracterização nutricional e compostos antioxidantes em resíduos de polpas de frutas tropicais. Ciência e Agrotecnologia, Lavras, v.35, p.554-559, 2011.

SWAIN, T; HILLS, W. E.The phenolic constituents of Punnusdomestica.Iquantitative analysis of phenolics constituents. Journal of the Science of Food and Agriculture, London, v.19, n.1, p.63-68, 1959.

VARANDA, E. A. Atividade mutagênica de plantas medicinais. Revista de Ciências Farmacêuticas Básica e Aplicada, Araraquara, v. 27, p.1-7, 2006.

VEDANA, M. I.S.; ZIEMER, C.; MIGUEL, O. G.; PORTELLA, A. C.; CANDIDO, L. M. B. Efeito do processamento na atividade antioxidante de uva. Alimentos e Nutrição, São Paulo, v.19, p.159-165, 2008.

VIEIRA, L, M.; SOUSA, M. S. B. ; MANCINI FILHO, J.; LIMA, A . Fenólicos totais e capacidade antioxidante in vitro de polpas de frutos tropicais. Revista Brasileira de Fruticultura, Jaboticabal, v.33, N. 4 p.888-897, 2011.

VILLAÑO, D.; FERNANDEZ-PCHÓN, M.S.; TRONCOSO, A.M.; GARCIA-PARRILLA, M.C. influence of enological practices on the antioxidant activity of wines. Food Chemistry, Oxford, v.95, p.394-404, 2006.

WANG, M. Y.; WEST, B.; JENSEN, C. J.; NOWICKI, D.; SU, C., PALU, A. K., ANDERSON, G. Morinda citrifolia (Noni): A literature review and recent advances in Noni research. Acta Pharmacologica Sínica, Shangai, v. 23, n. 12, p. 1127-1141, 2002. 